of this equipment somewhat delayed the adoption of type-printing telegraphs in Great Britain, but the whole supplies of the telegraph system are now being manufactured at home. It is hoped that the establishment of the teleprinter exchange service which is being introduced by the Post Office as an adjunct to the public telephone switching system will produce a further extensive demand for these ingenious machines. Before the year 1912, when the telephone service of Great Britain was transferred to the Post Office, a large portion of the equipment was purchased from abroad. Now the proportion of foreign material purchased by the Post Office is less than one per cent of the whole. A great impetus was given to the mass production of apparatus on precision principles in 1922 by the general adoption of standardised types of automatic exchanges. This policy encouraged other nations to follow suit and export markets to several countries were opened up for automatic telephone equipment manufactured in Great Britain. The circuits and mechanisms developed for automatic exchanges opened up independent fields of application in other directions, such as the supervisory control of electrical power plant, centralised railway control and the electrical equipment of the totalisators now operating on racecourses. Telephone manufacturers were quick to take advantage of these applications.

\section{Telephone Development}

THE economic blizzard from which the world is now suffering has affected the rate of telephone development in Great Britain to a smaller extent than in any other of the principal nations. Sir Thomas Purves states that the net increase per annum in Great Britain in recent years has been about 125,000 stations. In the last complete year (1931-32) it fell to 84,000 . Nevertheless, it is the largest increase recorded in any country of the world for the same period. For the whole of Europe, outside of Great Britain, the net increase was less than 200,000 . In some countries the number of cessations of service exceeds the number of new subscribers and a net loss is registered. In North America, for example, the net loss is about 550,000 stations. For the current year, it is probable that there will be a net increase in Great Britain of about 80,000 and that many of the countries of Europe will show actual losses. In America there will be a large loss. If a revival of trade occurs, the telephone development of Great Britain will go forward by leaps and bounds. In the matter of underground, telegraph and telephone cables, Great Britain has been from the first a pioneer. For building open telegraph and telephone lines it is still necessary to depend on Norway and Sweden for slow-grown raw timber. English and Scottish mountain pine and Canadian and Australian timber have proved disappointing. The use of poles of metal and concrete has been investigated on numerous occasions, but so far the cost of these alternatives has proved prohibitive. The timber used for general construction purposes is obtained entirely from home and Empire sources. The whole of the extensive radio plant and apparatus for long-distance communication used by the Post Office is of British manufacture.

\section{Recent Developments in the Utilisation of Electricity}

IN his inaugural address as chairman of the NorthWestern Centre of the Institution of Electrica] Engineers, Mr. G. F. Sills discussed a very large number of recent developments in the utilisation of electricity. One of the most important and most promising of electric devices is the mercury aro rectifier. When supplied with direct current, it can be made to generate alternating current voltage at any frequency. It can also supply direct current when supplied with alternating current. It provides a link between a.c. and d.c. systems which works either way. Batteries can thus be used as a reserve on a.c. systems. One of the most important applications is to feed single-phase railways from a three. phase system at a different frequency. The stand. ardisation of systems of supply for electric railways is thus not likely to lead to much trouble, as by the aid of the rectifier any kind of electric supply can be converted into any other. By its use it will soon be possible to transmit power by high-voltage direct current and this will lead to considerable economies in transmission. Obstruction lights are now being placed on power lines for marking obstacles along airways. They generally consist of neon tubes operated either at high or low voltages. They are used also to indicate high buildings and wireless masts. The light gives a large splash of red colour and is easily distinguished from other lights near the ground. Another interesting application is the reading of consumers' electric meters by means of telephone lines, the connexion being made through the power company's connexion with the telephone exchange. A device for indicating the presence of a dangerous amount of coal gas is also described. It works automatically, closing an alarm circuit, and it can be made to switch on an electric fan to clear the dangerous area.

\section{Manufacture of Lenses}

The presidential address of Mr. W. Taylor to the Institution of Mechanical Engineers on October 28 was mainly devoted to the application of mechanical engineering to the production of lenses, particularly photographic lenses, which to-day are made by the tens of thousands. One of the characters of mechanical engineering, he said, is the extraordinary accuracy regularly attained in its best products. One thousandth of an inch is approximately the limit of accuracy which can be attained in the ordinary machining of metal with cutting tools, one ten thousandth the order of accuracy by grinding and lapping; but in making the best photographic lenses and other optical instruments of precision, the accuracy of the surfaces of the elements, such as lenses, prisms and mirrors, must be from one hundred thousandth to a few millionths of an inch, and this accuracy is attained in everyday working, not only by skilled artist craftsmen, but also by less skilled

No. 3289, VoL. 130] 